\title{
"O que temos nós mulheres que atrai tanta violência?"1: A Mediação Penal de Gênero como método de tratamento de conflitos $^{2}$
}

\author{
"¿Qué tenemos las mujeres que atrae tanta violencia?": La Mediación \\ Penal de Género como método de tratamiento de conflictos \\ "What do we women have that attracts so much violence?": The Criminal \\ Mediation of Gender as a method of handling conflicts
}

\section{Gabrielle Scola Dutra ${ }^{3}$}

\begin{abstract}
Resumo
A violência de gênero está atrelada com a manutenção de um sistema hierárquico e de poder instituído pelo patriarcado que origina diversos conflitos. Dessa forma, a presente pesquisa, através do método de abordagem dedutivo, instruída por uma análise procedimental bibliográfica, promove discussões a respeito da implementação da Mediação Penal de Gênero como proposta complementar ao processo penal no que concerne aos novos métodos de tratamento de conflitos. Dessa forma, o objetivo da discussão é trazer à baila a Mediação como mecanismo que contribui para a emancipação e o empoderamento da mulher na sociedade atual, ao passo que promove uma retomada de consciência crítica dos indivíduos, bem como acarreta na desconstrução de estereótipos nas relações entre os gêneros e na fomentação de métodos não-violentos de tratamento de conflitos, tendo em vista a importância da (res)significação dos papéis sociais no processo de socialização, pois a construção da cidadania feminina na seara das discussões de gênero se dá através do reconhecimento da mulher como indivíduo integrante do tecido social pluralista.
\end{abstract}

Palavras-Chave: Empoderamento Feminino, Mediação Penal de Gênero, Método de Tratamento de Conflitos, Violência contra a mulher.

\section{Resumen}

La violencia de género está ligada al mantenimiento de un sistema jerárquico y de poder instituido por el patriarcado que origina diversos conflictos. De esta forma, la presente investigación, a través del método de abordaje deductivo, instruido por un análisis procedimental bibliográfico, promueve discusiones acerca de la implementación de la Mediación Penal de Género como propuesta complementaria al proceso penal en lo que concierne a los nuevos métodos de tratamiento de conflictos. De esta forma, el objetivo de la discusión es traer a la baila la Mediación como mecanismo que contribuye a la emancipación y el empoderamiento de la mujer en la

\footnotetext{
${ }^{1}$ Frase da teóloga feminista e filósofa brasileira Ivone Gebara, retirada da crônica: "quando as mulheres atraem violência" (KOINONIA, 2007).

${ }^{2}$ Artigo apresentado no II Seminário Latino-Americano de Estudos em Cultura - SEMLACult em Fóz do Iguaçu/PR, Brasil, 2018.

${ }^{3}$ Mestranda em Direito pela Universidade Regional Integrada do Alto Uruguai e das Missões - URI, campus Santo Ângelo. Bolsista CAPES. Pós-graduanda em Filosofia na Contemporaneidade pela URI-SA. Graduada em Direito pela URI-SA. Membro do grupo de pesquisa: "Conflito, Direitos Humanos e Cidadania" e "Tutela dos Direitos e sua Efetividade", ambos cadastrados no CNPQ e vinculados ao Programa de Pós-Graduação Stricto Sensu em Direito, Mestrado e Doutorado da URI; Santo Ângelo, Rio Grande do Sul, Brasil; e-mail: gabriellescoladutra@gmail.com.
} 
sociedad actual, mientras que promueve una retomada de conciencia crítica de los individuos, así como acarrea en la deconstrucción de estereotipos en las relaciones entre los géneros y en la fomentación de métodos no violentos de tratamiento de conflictos, teniendo en cuenta la importancia de la (s) significación de los papeles sociales en el proceso de socialización, pues la construcción de la ciudadanía femenina en la mina de las discusiones de género se da a través del proceso, el reconocimiento de la mujer como individuo integrante del tejido social pluralista.

Palabras claves: Empoderamiento Femenino; Mediación Penal de Género; Método de Tratamiento de Conflictos; Violencia contra la mujer.

\begin{abstract}
Gender violence is linked to the maintenance of a hierarchical system and power established by patriarchy that gives rise to several conflicts. Thus, the present research, through the method of deductive approach, guided by a bibliographic procedural analysis, promotes discussions about the implementation of the Criminal Mediation of Gender as a complementary proposal to the criminal process regarding the new methods of handling conflicts. Thus, the purpose of the discussion is to bring to light Mediation as a mechanism that contributes to the emancipation and empowerment of women in today's society, while promoting a resumption of critical awareness of individuals, as well as entails the deconstruction of stereotypes in relationships between gender and the promotion of non-violent methods of conflict treatment, given the importance of the (re) significance of social roles in the socialization process, since the construction of female citizenship in the area of gender discussions takes place through recognition of women as an integral part of the pluralistic social fabric.
\end{abstract}

Keywords: Female Empowerment, Gender Criminal Mediation, Conflict Treatment Method, Violence against women.

\title{
1. Introdução
}

A existência do modelo patriarcal de dominação compreende uma estrutura hierárquica, a qual impõe padrões sociais, de forma violenta, aos indivíduos mais vulneráveis de determinado espaço social. Nesse sentido, no que concerne ao papel que a violência desempenha no conflito entre os gêneros, principalmente em relação à figura da mulher, tal remete ao desenvolvimento de categorias sociais, culturais e históricas que permitem a ascensão de espaços que fomentem práticas violentas sob os corpos das mulheres, quando da resolução de situações conflitivas. Nessa ótica, o conflito advindo do sistema patriarcal está intimamente atrelado ao forjamento das identidades femininas perante uma sociedade multicultural $^{4}$ e pós-moderna. ${ }^{5}$

\footnotetext{
${ }^{4} \mathrm{O}$ multiculturalismo "descreve as características sociais e os problemas de governabilidade apresentados por qualquer na qual diferentes comunidades culturais convivem e tentam construir uma vida em comum, ao mesmo tempo em que retêm algo de sua identidade original. Refere-se às estratégias e políticas adotadas para governar ou administrar problemas de diversidade e multiplicidade gerados pelas sociedades multiculturais" (HALL, 2003, p. 83).

${ }^{5} \mathrm{O}$ termo sociedade pós-moderna "[...] representa a passagem da sociedade antiga para a moderna (ou a evolução de uma para a outra), que teria iniciado no século XVIII, embora muitos autores a datem nos idos dos anos de 1950 à década de 70, e que se relaciona com evolução, progresso, desenvolvimento, globalização
} 
Dessa maneira, o conflito de gênero deve ser (re)pensado a partir de novas formas de tratamento de conflitos, como a Mediação Penal de Gênero, a qual é um mecanismo de desconstrução da cultura do litígio através de processos democráticos pautados no entendimento pelo diálogo entre os conflitantes, no sentido do engajamento recíproco das partes em prol da pacificação social e da potencialização de um espaço comum. Sendo assim, é cediço afirmar que o contexto social de muitas mulheres é sedimentado pela dominação masculina, portanto, projeta-se um ambiente vulnerável e propicio à prática da violência sob os corpos das mulheres, motivo pelo qual justifica-se a necessidade de implementar métodos complementares à Justiça Criminal.

Sobretudo, o processo, embora paulatino, da busca pela igualdade de gênero sofre entraves advindos da má gestão do conflito. Logo, a partir da premissa supracitada, compreende-se que a Mediação Penal de Gênero seja um método de tratamento complementar de conflitos que possibilite a condução do conflito por caminhos autocompositivos que proponham a harmonização dos vínculos entre as partes envolvidas. Dessa forma, constata-se que a transformação dos conflitos pela mediação, permite reconhecer as múltiplas identidades culturais (os Outros) que convivem e compartilham o mesmo espaço social perfectibiliza novas significações de entendimento. Portanto, a mediação representa uma ferramenta adequada para a efetividade dos Direitos Humanos.

\section{A Mediação Penal de Gênero como política de cidadania e tratamento de conflitos que envolvem violência contra a mulher}

No que concerne ao espaço social das relações interacionais entre os indivíduos, percebe-se a existência de conflitos que povoam a totalidade social, principalmente, em decorrência dos papéis sociais impostos aos sujeitos. Diante de tal premissa, no que se refere a construção social do conflito, entra em ascensão a figura do homo sociologicus que se encontra no "[...] ponto de intersecção entre a sociedade e os indivíduos" (DAHRENDORF, 1969, p. 40). À título conceitual, pode-se asseverar que o homem sociológico nasce do estabelecimento de papéis sociais pré-constituídos.

Por outro lado, a humanidade sobrevive e evolui pelo desenvolvimento do conflito, no que concerne a sedimentação de papéis sociais sob os indivíduos como percepção do agir

econômica, mundialização da economia, promovendo, dessarte, uma ruptura com a ordem social existente até então, no caso, a tradicional” (LYRA, 2011, p. 60). 
social perante a intervenção humana. Destarte, o que se promove são os choques de perspectivas e percepções de mundo que se potencializam com o escopo de fragmentar a resistência do homem real e fazê-lo padecer às chagas atributivas do homo sociologicus como um projeto ardilosamente arquitetado pela civilização dominante para dilacerar a complexidade do sistema de existência humana. Sobretudo, a ideia do homo sociologicus é a produção do homem projetado a partir de um paradigma simplista, a qual pretende estipular um ideal de normalidade em um contexto social complexo que requer fragmentação de concepções fixas.

Dito de outro modo, o papel social é concebido como "uma forma de comportamento preestabelecido para uma regra de comportamento individual, passando de um conceito sociológico para um conceito psicossociológico elementar" (DAHRENDORF, 1969, p. 46). Sendo assim, "os seres humanos demonstram, entretanto, maior habilidade para se envolver em conflito do que para lidar com eles [...]” (FIORELLI; FIORELLI; MALHADAS JUNIOR, 2008, p. 48).

Desse modo, a situação conflitiva desenvolve uma compreensão atrelada à violência e sua instrumentalização quando há o ato do enfrentamento e o comportamento hostil, no sentido de prejudicar, ou seja, quando o Outro torna-se um inimigo. Nesse ponto, o instinto da agressividade surge sob a justificativa de um determinismo biológico inerente aos seres humanos, ao passo que "[...] a agressividade é uma espécie de instinto natural, que como todo instinto está a serviço da conservação da vida individual ou da vida da espécie. Então pode haver agressividade sem hostilidade, ou seja, sem conflito" (FREUND, 1995, p. 60).

Contudo, Ralf Dahrendorf atenta no fato de que:

Mesmo que o biológico revele alguns aspectos da pessoa humana, tranquiliza-nos o fato de que o corpo não é o essencial em nós e que conceitos e teorias biológicas não afetam a integridade de nossa individualidade. Precisamos até certo grau assimilar o homem biológico e custa-nos relativamente pouco a identificação com o mesmo (DAHRENDORF, 1969, p. 36).

Portanto, "[...] a hostilidade é de ordem emocional, ou seja, se manifesta em um momento determinado e não possui continuação, é de natureza transitória" (FREUND, 1995, p. 60). No mesmo sentido, o sentimento de hostilidade nas duas partes conflitantes, porém, "é suficiente que uma delas o manifeste para criar uma situação conflitiva. Por último, há uma graduação na hostilidade, desde a simples ameaça com intuito a inspirar medo ao Outro, até ataca-lo com violência" (FREUND, 1995, p. 60). Com efeito, a situação conflitiva, em geral, se manifesta a partir de uma reinvindicação justiça, ou seja, um direito potencialmente 
ameaçado, "[...] um direito que se compreende lesionado, desconhecido ou desprezado" (FREUND, 1995, p. 60).

Sobretudo, o conflito aqui é gerado quando sob o corpo político do indivíduo é atribuído um papel social, tendo em vista a situação de injustiça que lhe é posta. Nessa banda, o conflito também surge como situação imposta com o condão de dominar o Outro, bem como lhe impor uma medida coercitiva, de forma abrupta, como força hierárquica que produz uma opressão estrutural no interior da relação interacional, ou seja, o rompimento da resistência do Outro faz com que algum direito lhe seja negado ou não reconhecido a partir do emaranhado de sistemas de tensões promovido pelo conflito. Não obstante, uma das características do conflito é o risco do enfrentamento. Assim, surge uma relação de forças pelo emprego da violência em consonância com a vontade de aniquilar o Outro, por fím, o processo se desenvolve numa concepção de luta (FREUND, 1995).

Destarte, a título conceitual:

A violência é desencadeada brutalmente sem retroceder a nada, nem perante as proibições sociais nem convenções jurídicas e morais. Se fixa a si mesma, seus limites estão sempre mudando. Tudo é possível, tudo está permitido. Se desenvolve sem cálculo de meios (e incluída muitas vezes todos os meios são bons) porque não tem um objetivo determinado, e o inimigo não está concretizado (FREUND, 1995, p. 63).

A produção do inimigo se dá na formação do conflito adversarial, quando há partes antagonistas. Por suposto, a relação antagônica predispõe ao duelo e ao binômio amigo/inimigo, no que concerne a isso, é conciso asseverar que na relação antagônica não há possibilidade de diálogo democrático. Ademais, “o conflito introduz uma ruptura e ao mesmo tempo desbloqueia a situação, porque em geral põe subitamente às partes na presença do que realmente importa, as consequências e os riscos" (FREUND, 1995, p. 77).

Quando a solução da conflitividade se dá pela violência ocorre uma falsa derrota de um lado do liame conflitivo, fato que conduz uma trégua, porém "[...] permite voltas à hostilidade quando a situação for propicia [...]" (FREUND, 1995, p. 222). Porque "a vitória não é mais do que o instante efêmero e pontual do triunfo designado pela rendição do outro, que aceita ou não sua derrota" (FREUND, 1995, p. 222). Sendo assim, "uma vitória não é fatalmente significado de uma persistência de uma sólida constituição da sociedade" (FREUND, 1995, p. 223).

A título histórico, há um crescente fértil no que tange à propagação de conflitos entre os gêneros, bem como tal acontecimento provoca consequências, mais abruptas, sob os corpos das mulheres, tendo em vista a condição que culturalmente lhes foi imposta, principalmente, 
pela naturalização de preceitos patriarcais ${ }^{6}$ atribuídos pelo controle social das instituições sob seus corpos, o que, consequentemente, provoca a violência e outras formas estruturais de violação dos seus Direitos Humanos. Destarte, já asseverou a teóloga feminista Ivone Gebara: “o que temos nós mulheres que atrai tanta violência?" (KOINONIA, 2007, s.p.).

Nessa conjuntura, o patriarcalismo sempre se ocupou da religião e da cultura sob o enfoque das tradições para determinar a estrutura social em que a mulher deveria ser sobreposta, provocando um espaço conflitivo de disputa entre os gêneros. Com base em tais constatações, é estabelecida uma premissa fundamental no que se refere ao gênero feminino, a qual está incluída em parâmetros de segregação e opressão ocasionados pela violência cotidiana imposta pelo poder masculino, qual seja, a constatação de que ser mulher na sociedade contemporânea é um rotineiro desafio, perante a resistência da ordem patriarcal de atribuir padrões sociais ideias de identidade à figura feminina. Nessa ótica, a violência contra a mulher é presente no entorno da sociedade, o que acarreta ao conflito do gênero em questão um incremento da construção de diversas ramificações das desigualdades.

Logo, tais repercussões migram para o terreno da (im) possibilidade de desmistificar o conflito eivado pela violência. Nesse particular, é imprescindível que se instituam novos métodos de tratamento de conflitos em prol do gênero feminino diante das demandas sociais, para que se garanta o reconhecimento e a concretização dos direitos das mulheres, bem como a sua plena eficácia quando da desconstrução dessas incongruências entre os gêneros. Sobretudo, pode-se afirmar que a mulher “[...] é um ser religioso, ético e jurídico, por ser um ser que interliga, através da linguagem, realidade vivida e realidade a ser vivida" (HAHN in BERTASO; VERONESE; PIAIA (Orgs.), 2015, p. 27). Na medida em que o conflito se regula, tanto pela força quanto pela negociação, o método mais adequado é aquele que se utiliza da invocação da democracia e do diálogo de forma complementar (FREUND, 1995, p. 237).

À vista disso, no que concerne a aplicabilidade de métodos de tratamento de conflitos, a mediação "[...] representa uma autocomposição assistida, o processo pelo qual uma terceira pessoa facilita a comunicação entre as partes, almejando a solução e a prevenção de conflitos" (SALES, 2003, p. 40). Outrossim, a mediação se fundamenta no entendimento do conflito como uma evolução a partir do diálogo entre os agentes envolvidos, tendo por escopo fundamental promover um tratamento autocompositivo (tomar uma decisão), facilitando a

\footnotetext{
6 “[...] o patriarcado consiste num sistema que integra relações sociais hierárquicas e de dominação em que os homens detêm direitos e poderes negados às mulheres, o que as torna inferiores socialmente [...]" (HAHN in GIMENEZ; LYRA (Orgs.), 2016, p. 59).
} 
comunicação e possibilitando o amadurecimento da situação projetada pelo conflito pelo pensar através da alteridade. Nessa conformidade "o mediador é quem oferece, através de seus métodos próprios, maior possibilidade de solução satisfatória de conflitos" (SALES, 2003, p. 40).

Observa-se, no que concerne à possibilidade de se aplicar a mediação nos casos de conflitos entre os gêneros, principalmente, referente a atribuição de papéis sociais impostos à figura da mulher, em face da necessidade de se originar pactos autocompositivos. Assim sendo, a Mediação Penal de Gênero é caracterizada por ser uma técnica de comunicação nãoviolenta $(\mathrm{CNV})^{7}$ que pode ser utilizada de forma contributiva no que se refere à concretização de uma política de cidadania e fomento de uma cultura de paz diante da prática de crimes que envolvem violência contra a mulher. Sobretudo, “[...] a CNV serve como recurso valioso para comunidades que enfrentam conflitos violentos ou graves tensões de natureza étnica, religiosa ou política" (ROSENBERG, 2006, p. 31).

Dessa maneira, José Luis Bolzan de Morais e Fabiana Marion Spengler estabelecem que com a ajuda no mediador,

[...] os envolvidos buscarão compreender as fraquezas e fortalezas de seu problema, a fim de tratar o conflito de forma satisfatória. Na mediação, por constituir um mecanismo consensual, as partes apropriam-se do poder de gerir seus conflitos, diferentemente da Jurisdição estatal tradicional na qual este poder é delegado aos profissionais do direito, com preponderância àqueles investidos das funções jurisdicionais (MORAIS; SPENGLER, 2012, p. 132).

Sobretudo, sabe-se que para ocorrer o entendimento do conflito entre os gêneros não somente é preciso que se determine o nexo causal entre o agente e o fato gerador da relação antagônica conflitiva, como também identificar o funcionamento e o contexto fatorial que manipula a evolução negativa do ato. Logo, insta discorrer que "[...] as ideologias foram grandes aliadas para a conservação de estruturas de desigualdade, que geram violência institucional, intrafamiliar, de gênero e doméstica" (HAHN in GIMENEZ; LYRA, 2016, p. 59).

Exemplo disso é que a relação entre mediação e direito penal encontra fundamentação no sentido de que, a consensualidade atingida pelo método da mediação como método de CNV atinge "[...] os critérios de carência e necessidade da tutela penal, de tal forma que o resultado seria a renúncia à tutela, seja pela satisfação da vítima, pela reparação do dano ou

\footnotetext{
${ }^{7}$ A comunicação não-violenta (CNV) é "[...] uma abordagem específica da comunicação - falar e ouvir - que nos leva a nos entregarmos de coração, ligando-nos a nós mesmos e aos outros de maneira tal que permite que nossa compaixão natural floresça" (ROSENBERG, 2006, p. 21).
} 
pelo alcance das finalidades preventivas, derivado da estabilização das expectativas normativas" (SICA, 2007, p. 78). Por conseguinte, é imprescindível mencionar que a mediação não deve substituir o processo e a pena, justamente por ser ela, uma proposta de complemento ao sistema penal, de forma que desconstrua a carga punitivista com que o direito penal encara a imposição das penas (SICA, 2007, p. 78). Nesse ínterim, "qualquer fracasso da mediação leva à recondução do caso ao sistema penal, na tentativa de impedir que a situação penal do delinquente seja agravada devido a esse fracasso" (DELMAS-MARTY apud SICA, 2007, p. 80).

Compreende-se, assim, que com a dinamicidade das relações conflitivas a mediação penal de gênero deve ser uma possibilidade no âmbito do direito de emergir teorias do conflito, as quais demonstrem o entendimento da incongruência através do diálogo, de maneira que se utilizem de métodos que causem no "[...] outro, a diferença, ou seja, inscrever a diferença no tempo como produção do novo. O conflito como uma forma de inclusão do outro na produção do novo: o conflito como outridade que permita administrar, com o outro, o diferente para produzir a diferença" (WARAT, 2004, p. 61).

Dessa forma, os conflitos são extintos a partir do desenlace amorfo, "o conflito se acaba em uma espécie de corrupção que pode parecer interminável, não sabendo como sair finalmente do mal-estar, se procede a decomposição interna dos objetivos e das energias em ambos os campos" (FREUND, 1995, p. 208). Nessa ótica, os conflitos acabam quando ocorre a despolarização do ambiente conflitivo a partir da potencialização das partes envolvidas no liame quando da utilização de mecanismos de tratamento de conflitos e da condução do método por um terceiro:

Se trata de toda uma arte destinada a fazer fracassar a violência graças à intervenção de terceiros mediadores, que hábeis com o manejo da linguagem, dissolvem os impulsos passionais, filtram os motivos do conflito, expurgam as ameaças devido à relação antagônica, a distância pela proibição que há em toda a comunicação direta entre eles (FREUND, 1995, p. 208).

Nesse sentido, “[...] a mediação penal situa-se numa fronteira móvel ou, justamente, tem a pretensão de demarcar a fronteira da penalidade numa perspectiva mais humanista, menos inflexível e centrada na participação popular na administração da justiça" (SICA, 2007, p. 80). Outrossim, a norma penal vigente afeta o acesso à cidadania das mulheres vítimas de crimes praticados com violência no sentido de "perpetrar e cristalizar os estereótipos de gênero, fomentando a desigualdade nas relações de poder entre homens e mulheres. É a desigualdade dessas relações de gênero que gera um ambiente propício às situações de violência [...]" (SOUZA; ADESSE, 2005, p. 38-39). 
Em suma, a Mediação Penal de Gênero é um método de tratamento de conflitos utilizado para analisar demandas sociais que visam estabelecer rupturas relacionadas ao gênero, classe e cultura em prol da emancipação das mulheres e em desfavor da violência que é presente no tecido social. À vista disso, é como se houvesse uma seleção papéis sociais impostos que devam integrar os segmentos exclusivos da sociedade sem que se contextualizem as especificidades de gênero. Sobretudo, a mediação reafirma a importância de se desconstruir tais impasses entre os gêneros, pois a construção da cidadania feminina na seara das discussões de gênero se dá através do empoderamento e da emancipação feminina, características que provocam o devido reconhecimento e a inclusão do gênero feminino na seara social.

\section{Considerações Finais}

A povoação de cotidianos por premissas que são totalizadas pela violência promove contornos conflitivos no que se refere às relações entre os gêneros. Nesse sentido, é necessário potencializar uma dialética que possibilite a construção de uma forma de alteridade que fragmente todo um pensamento enrijecido por dinâmicas operacionalizadas por um cunho violento. Em suma, é imprescindível que ocorra uma (re)significação democrática dos conflitos e das relações humanas a partir do diálogo como uma epistemologia pautada na humanização, promovendo a pacificação social e não uma relação binária constituída e manipulada pela instrumentalidade da violência a partir da vitória/derrota, amigo/inimigo.

\section{Referências}

DAHRENDORF, Ralf. Homo Sociologicus. Tradução de Manfredo Berger, Rio de Janeiro: Tempo Brasileiro, 1991.

FIORELLI, José Osmir. FIORELLI, Maria Rosa. MALHADAS JUNIOR, Marcos Julio Olivé. Mediação e solução de conflitos: teoria e prática. São Paulo: Atlas, 2008.

FREUND, Julien. Sociología del conflicto. Traduccion de Juan Guerrero Roiz de la Parra. Madrid: Ministério de Defensa, Secretaria General Técnica, D.I.., 1995. 
GEBARA, Ivone. Quando as mulheres atraem violência. Disponível em: $<$ http://www.koinonia.org.br/tpdigital/detalhes.asp?cod_artigo $=77 \&$ cod_boletim=4\&tipo=Cr \%C3\%B4nica>. Acesso em: 08 abr. 2018.

GIMENEZ, Charlise Paula Colet. SPENGLER, Fabiana Marion. O mediador na resolução 125/2010 do CNJ: um estudo a partir do Tribunal Múltiplas Portas. Águas de São Pedro: Livro Novo, 2016.

HAHN, Noli Bernardo. Algumas notas introdutórias sobre inter-relação entre Direito, Cultura e Religião. In: BERTASO, João Martins. VERONESE, Osmar. PIAIA, Thami Covatti (Orgs.). Diálogo e Entendimento: Direito e multiculturalismo \& políticas de cidadania e resolução de conflitos: tomo 6. Campinas, SP: Millenium Editora, 2015, p. 17-29.

HAHN, Noli Bernardo. Um direito com sabor de injustiças e humilhações: um ensaio relacionando hermenêutica de gênero e direitos humanos. In: GIMENEZ, Charlise Paula Colet. LYRA, José Francisco Dias da Costa. Diálogo e entendimento: Direito, Multiculturalismo \& políticas de cidadania e resolução de conflito: tomo 7. Campinas, SP: Millennium Editora, 2016, p. 51-70.

HALL, Stuart. Da diáspora: identidades e mediações culturais. SOVIK, Liv (Org.) Belo Horizonte: Editora UFMG.

LYRA, José Francisco Dias da Costa. A expansão do Direito Penal na Pós-Moderna Sociedade do Risco: O Controle Penal e suas (im) possibilidades. In: (Re) Pensando Direito. V. 1. $\quad \mathrm{N}^{\mathrm{o}} \quad$ 2. 2011. P. 55-78. Disponível em: $<$ http://local.cnecsan.edu.br/revista/index.php/direito/article/view/34>. Acesso em: 24 jun. 2018 .

MORAIS, Jose Luis Bolzan de. SPENGLER, Fabiana Marion. Mediação e arbitragem: alternativa à jurisdição!. 3 ed. rev. E atual. Com o Projeto de Lei do novo CPC brasileiro (PL 166/2010), Resolução 125/2010 do CNJ. Porto Alegre: Livraria do Advogado Editora, 2012.

ROSENBERG, Marshall B. Comunicação não-violenta: Técnicas para aprimorar relacionamentos pessoais e profissionais. São Paulo: Ágora, 2006.

SALES, Lília Maia de Morais. Justiça e Mediação de conflitos. Belo Horizonte: Del Rey, 2003.

SICA, Leonardo. Justiça Restaurativa e Mediação Penal: O Novo Modelo de Justiça Criminal e de Gestão do Crime. Rio de Janeiro: Lumen Juris Editora, 2007.

SOUZA, Cecília de Melo; ADESSE, Leila. Violência sexual no Brasil: perspectivas e desafios, Brasília. Secretaria Especial de Políticas para as Mulheres. 2005.

WARAT, Luis Alberto. Surfando na pororoca: ofício do mediador. Florianópolis: Fundação Boiteux, 2004. 